a general population. A prevalence study, f Clin Epidemiol 1991;11: 1147-57.

12 Waters W/E. Headache and blood pressure in the community. BMF 1971;: 142-3.

13 Weiss NS. Relation of high blood pressure to headache, epistaxis and selected other symptoms: the United States Health Examination survey of adults. N Engl Y Med 1972;287:631-3.

14 Chen TC, Leviton A, Edelstein S, Ellenberg JH. Migraine and other diseases in women of reproductive age. Arch Neurol 1987;44:1024-8.
15 Markush RE, Karp HR, Heyman A, O'Fallon WM. Epidemiologic study of migraine symptoms in young women. Neurology 1975;25:430-5.

16 Ziegler DK, Hassanein R, Couch JR. Characteristics of life headache histories in a non-clinic population. Neurology 1977;27:265-9.

17 Gill JS, Shipley MJ, Tsementzis SA, Hornby R, Gill SK, Hitchcock ER, et al Cigarette smoking. A risk factor for hemorrhagic and non hemorrhagic stroke. Arch Intern Med 1989;149:2053-7.

(Accepted 26 May 1993)

\title{
Muslims with non-insulin dependent diabetes fasting during Ramadan: treatment with glibenclamide
}

\author{
J Belkhadir, H El Ghomari, N Klöcker, A Mikou, M Nasciri, M Sabri
}

Medical Department E, University Hospital Ibn Sina, Rabat, Morocco $\mathrm{J}$ Belkhadir, professor

Department of Endocrinology and Metabolic Diseases, University Hospital Ibn Rochd, Casablanca, Morocco

H El Ghomari, physician

Hoechst AG, Medical Services Corporate, K607; D-6230 Frankfurt, Germany

N Klöcker, physician

Clinic for Endocrinology and Diabetology, Hakim, Casablanca

A Mikou, physician

Clinic for Endocrinology and Diabetology, 2 bd Zerktouni, Casablanca

M Nasciri, physician

Department of

Endocrinology and

Metabolic Diseases,

Polyclinic CNSS Ziraoui,

Casablanca

M Sabri, physician

Correspondence to: Dr Klöcker.

BMF 1993;307:292-5
Abstract

Objective-To compare the efficacy of two glibenclamide regimens in patients with non-insulin dependent diabetes who were fasting during Ramadan and regular glibenclamide treatment in the nonfasting group.

Design-Non-randomised control group of patients who did not fast during Ramadan and two groups of patients who fasted randomised equally to one of two regimens: to take their usual morning dose of glibenclamide in the evening and their usual evening dose before dawn; or to follow this pattern but to reduce the total dose by a quarter.

Setting-Two university hospitals, one private hospital, and two private clinics in Casablanca and Rabat, Morocco.

Subjects -591 diabetic patients (198 men, 391 women, two unspecified) with similar duration of diabetes and length and amount of glibenclamide treatment, of whom 542 completed the study.

Main outcome measures-Serum fructosamine and total glycated haemoglobin concentrations and number of hypoglycaemic events.

Results-At the end of Ramadan there were no significant differences between the groups in fructosamine concentration $(400 \mu \mathrm{mol} / /$ in controls and $381 \mu \mathrm{mol} / \mathrm{h}$ and $376 \mu \mathrm{mol} / \mathrm{h}$ in the fasting groups); percentage of glycated haemoglobin $(14 \cdot 7 \%, 14.0 \%$, and $13.6 \%$ ); or number of hypoglycaemic events during Ramadan (11, 14, and 10).

Conclusion-Glibenclamide is effective and safe for patients with non-insulin dependent diabetes who fast during Ramadan. The easiest regimen is to take the normal morning dose (together with any midday dose) at sunset and any evening dose before dawn.

\section{Introduction}

About one billion people worldwide follow Islam, a basic principle of which is fasting from sunrise to sunset for one lunar month during Ramadan. This poses obvious problems for patients with diabetes, ${ }^{12}$ who mostly prefer not to accept the exemptions allowed for patients with certain illnesses. ${ }^{3}$ Although the prevalence of diabetes may be $3-5 \%$ in Islamic countries, ${ }^{4}$ the only studies of the problems experienced by diabetic patients during Ramadan have been on small groups (fewer than 60 patients) treated with several drugs. ${ }^{5-8}$ At least one of the studies examined only men. ${ }^{6}$ Two studies of fasting among healthy subjects also examined only men.910 We have therefore conducted a randomised controlled trial of different treatment regimens in a group of patients with non-insulin dependent diabetes living in two Moroccan cities who were being treated with glibenclamide.

\section{Patients and methods}

The study was performed at one university hospital, one private hospital, and two private clinics in Casablanca and one university hospital in Rabat. These sites were chosen to guarantee the inclusion of all social classes. The study lasted from 27 January to 8 May 1992 to include a run in and follow up of about four weeks each as well as the month of Ramadan (6 March to 5 April). During this time patients were asked to visit a study centre four times in predefined time windows of about one week each: at the start of run in (27 January to 7 February), at the start of Ramadan (24 February to $5 \mathrm{March}$ ), at the end of Ramadan (26 March to 4 April), and at the end of follow up (22 April to 8 May). Altogether 591 patients of both sexes were recruited. They were aged 33-80 (mean 55.5) years, had established non-insulin dependent diabetes (mean duration 7.6 years), and had been treated with glibenclamide $7 \cdot 5-20 \mathrm{mg}$ (mean $11 \mathrm{mg}$ ) for at least six months. Thus newly diagnosed diabetic patients and those whose response to glibenclamide was not yet known were excluded. The study centres were asked to recruit twice as many patients who planned to fast during Ramadan as those who planned not to fast.

All the selected patients gave their informed consent to the study. They were divided into three groups. Those who had elected not to fast during Ramadan acted as a substitute for a randomised control group, which would have created some ethical problems. The remaining patients, who had decided to fast, were randomised consecutively with sealed envelopes to one of two regimens. In one group patients took their normal daily doses of glibenclamide but reversed the pattern of doses so that they took their usual morning dose at $7 \mathrm{pm}$, after the break of fasting, and their usual evening dose at $4 \mathrm{am}$, with the last meal before fasting. The 126 patients in this group who had been taking another dose at midday, a common practice in the Mediterranean and tropical countries, added this to the dose taken in the evening. The patients in the other group also reversed their normal pattern of doses but took only $75 \%$ of their normal total daily dose of glibenclamide by reducing the amount taken in the morning. The 122 patients in this group who had been taking a dose at midday" divided this dose equally between the morning and evening doses.

At each visit to a study centre the patients' weight, blood pressure, and pulse rate were measured, and blood samples were taken for laboratory analysis. Patients' hypoglycaemic events were assessed retrospectively and rated on a six point scale. As far as possible the patients were asked to monitor glucose concentrations in their urine and were supplied with test strips. They were asked to monitor the first spontaneous release of urine after the start of fasting and after breaking their fast, to record the values in a booklet, and to discuss the results at the next visit. This 
self monitoring, however, was not part of the statistical evaluation.

All blood samples were collected every day by courier for analysis by CIRAB laboratories, Casablanca, and the investigators had no access to the results. The serum concentrations of fructosamine, ${ }^{11}$ total glycated haemoglobin, ${ }^{12}$ serum albumin, creatinine, cholesterol, and trigylcerides were measured. Fructosamine concentration and percentage of total haemoglobin that was glycated were measured because they have a close relation to the mean blood glucose concentration, and hence diabetic control, during the previous 2-4 weeks. Blood glucose profiles were not studied because of the varying times between the predawn meal, the sampling of blood, and the fear that removing too much blood might cause patients to break their fast in accordance with Islamic teachings. ${ }^{5}$

Differences between the three groups of patients at admission were studied by Kruskal-Wallis and $\chi^{2}$ tests and analysis of variance at a descriptive level of $5 \%$. Differences between groups in fructosamine and glycated haemoglobin concentrations at the start of Ramadan were taken into account in the analysis of group differences at the end of Ramadan (endpoint) by an analysis of covariance (covariate: value at start of Ramadan). If there was no difference between groups at the start of Ramadan an analysis of variance was performed. Because results were expected to be affected by the study centres, these analyses were carried out with the factors groups, centres, and group $\times$ centres interaction. ${ }^{13}$ The same procedure

TABLE I-Characteristics of patients on admission to study. Values are means (standard deviations) unless stated otherwise

\begin{tabular}{|c|c|c|c|c|}
\hline & \multicolumn{3}{|c|}{ Groups of patients } & \multirow[b]{2}{*}{ p Value } \\
\hline & $\begin{array}{l}\text { Control } \\
(n=194)\end{array}$ & $\begin{array}{c}\text { Full dose } \\
\text { of glibenclamide } \\
(n=199)\end{array}$ & $\begin{array}{l}\text { Reduced dose } \\
\text { of glibenclamide } \\
(n=198)\end{array}$ & \\
\hline $\begin{array}{l}\text { No of men } \\
\text { No of women } \\
\text { Age (years) } \dagger \\
\text { Weight }(\mathrm{kg}) \ddagger \\
\text { Body mass index }\left(\mathrm{kg} / \mathrm{m}^{2}\right) \ddagger \\
\text { Duration of diabetes (years) } \\
\text { Usual daily dose of glibenclamide }(\mathrm{mg}) \| \\
\text { Serum concentration of fructosamine }(\mu \mathrm{mol}) \int \\
\text { Glycated haemoglobin }(\%) \int\end{array}$ & $\begin{array}{l}56 \\
137 \\
57 \cdot 2(9 \cdot 0) \\
64 \cdot 9(11 \cdot 3) \\
25 \cdot 9(3 \cdot 9) \\
8 \cdot 53(6 \cdot 2) \\
11 \cdot 7(3 \cdot 5) \\
383(84) \\
14 \cdot 2(3 \cdot 3)\end{array}$ & $\begin{array}{l}75 \\
123 \\
54 \cdot 9(9 \cdot 3) \\
68 \cdot 6(10 \cdot 3) \\
26 \cdot 7(3 \cdot 8) \\
7 \cdot 03(5 \cdot 5) \\
10 \cdot 7(3 \cdot 1) \\
366(85) \\
13.7(3 \cdot 4)\end{array}$ & $\begin{array}{l}67 \\
131 \\
54 \cdot 8(9 \cdot 7) \\
67 \cdot 9(11 \cdot 4) \\
26 \cdot 7(4 \cdot 2) \\
7 \cdot 05(5 \cdot 35) \\
10 \cdot 7(3 \cdot 5) \\
352(82) \\
13 \cdot 2(3 \cdot 6)\end{array}$ & $\begin{array}{l}\text { NS } \\
0 \cdot 18 \\
0.02 \\
0.01 \\
0.06 \\
0.02 \\
0.02 \\
0.01 \\
0.01\end{array}$ \\
\hline
\end{tabular}

^See text for details of groups.

Data missing for $\nmid 10$ cases, $¥ 4$ cases, $\$ 13$ cases, and $\| 36$ cases.

TABLE II-Mean (standard deviation) doses of glibenclamide (mg) taken by the 542 patients who completed the study at each of the visits

\begin{tabular}{lccc}
\hline & \multicolumn{3}{c}{ Groups of patients $^{\star}$} \\
\cline { 2 - 4 } Visit & Control & $\begin{array}{c}\text { Full dose of } \\
\text { glibenclamide }\end{array}$ & $\begin{array}{c}\text { Reduced dose of } \\
\text { glibenclamide }\end{array}$ \\
\hline Start of run int & $11.5(3.4)$ & $10.7(3.2)$ & $10.7(3.3)$ \\
Start of Ramadanf & $11.4(3.4)$ & $10.7(3.2)$ & $7.9(2.9)$ \\
End of Ramadan§ & $11.8(3.6)$ & $10.7(3.3)$ & $10.7(3.5)$ \\
End of follow up\| & $12.2(3.7)$ & $11.2(3.3)$ & $10.9(3.4)$ \\
\hline
\end{tabular}

*See text for details of groups.

Data missing for $\nmid 5$ cases, $¥ 18$ cases, $\$ 20$ cases, and $\| 22$ cases.

TABLE II-Characteristics of the 542 who completed the study at the end of Ramadan. Figures are means (standard deviations)

\begin{tabular}{|c|c|c|c|}
\hline & \multicolumn{3}{|c|}{ Groups of patients* } \\
\hline & $\begin{array}{l}\text { Control } \\
(n=177)\end{array}$ & $\begin{array}{c}\text { Full dose of } \\
\text { glibenclamide } \\
(n=183)\end{array}$ & $\begin{array}{l}\text { Reduced dose of } \\
\text { glibenclamide } \\
(n=182)\end{array}$ \\
\hline \multicolumn{4}{|c|}{ Fructosamine concentration $(\mu \mathrm{mol} / /)$ : } \\
\hline At start of Ramadan & $\begin{array}{l}396(91) \\
400(102)\end{array}$ & $\begin{array}{l}367(80) \\
381(96)\end{array}$ & $\begin{array}{l}359(82) \\
376(98)\end{array}$ \\
\hline \multicolumn{4}{|c|}{ Glycated haemoglobin (\%): } \\
\hline $\begin{array}{l}\text { At start of Ramadan } \\
\text { At end of Ramadan }\end{array}$ & $\begin{array}{l}14.3(3 \cdot 6) \\
14 \cdot 7(3 \cdot 2)\end{array}$ & $\begin{array}{l}13.6(3.5) \\
14.0(2.9)\end{array}$ & $\begin{array}{l}13.2(3.6) \\
13.6(3.2)\end{array}$ \\
\hline \multicolumn{4}{|l|}{ Body weight $(\mathrm{kg})$ : } \\
\hline $\begin{array}{l}\text { At start of Ramadan } \\
\text { At end of Ramadan }\end{array}$ & $\begin{array}{l}65 \cdot 2(11 \cdot 4) \\
65 \cdot 7(11 \cdot 4)\end{array}$ & $\begin{array}{l}68 \cdot 2(10 \cdot 0) \\
69 \cdot 2(10 \cdot 0)\end{array}$ & $\begin{array}{l}68.2(10.9) \\
68.7(10 \cdot 8)\end{array}$ \\
\hline
\end{tabular}

${ }^{\star}$ See text for details of groups. applied to other laboratory measures. The frequencies of patients' hypoglycaemic episodes throughout the study period and during Ramadan were compared by Fisher's exact test. All statistical analyses were performed with the SAS system and were based on intention to treat so that all patients with at least one visit before and one after Ramadan were included, and data from beginning and end of Ramadan were used if available.

The calculation of sample size was based on the $\alpha$ adjusted ( $\alpha=0.017$; Sidak method) $t$ test of pairwise comparisons of glycated haemoglobin at the end of Ramadan. ${ }^{14}$ To detect a relevant difference between the means of two groups which is at least $55 \%$ of the standard deviation of glycated haemoglobin 69 evaluable patients per group were needed to achieve a power of $80 \%$. Thus the recommended sample size was 240 patients. Because we had at least 160 evaluable patients in each group the power of this study was $99.5 \%$ for the conditions of the sample size calculation. Also smaller group differences than in these conditions were detectable, a difference of $36 \%$ of the standard deviation of glycated haemoglobin with the usual power of $80 \%$.

\section{Results}

Of the 96 patients who dropped out of the study, 49 were lost to follow up because they did not attend the visits at the end of Ramadan or of follow up (17 from the control group and 16 each from the two fasting groups). There were no significant differences ( $\alpha=10 \%)$ for either the laboratory values or the demographic characteristics between these 49 patients and the 542 eligible for intention to treat analysis. A further 62 patients made protocol violations that excluded them from analysis of patients who observed the study's protocol. These two analyses, however, gave equivalent results.

Table I shows details of the 591 patients (198 men, 391 women, and two not specified) initially recruited. The two randomised groups had similar ratios of men to women (about 1:2) and body mass index (weight $\left.(\mathrm{kg}) /(\text { height }(\mathrm{m}))^{2}\right)$. The patients in the self selected control group, however, were older, weighed less, had been diabetic for longer, and took larger doses of glibenclamide. Nevertheless, among the 542 patients who completed the study, the results for the control group were similar to those of the other groups. To judge from the values for percentage of glycated haemoglobin and fructosamine concentration found with well controlled diabetes (ranges $9-12 \%$ and 180 $285 \mu \mathrm{mol} / \mathrm{l}$ respectively), most of our patients (457/ 542) had poorly controlled diabetes: their mean (SD) percetage of glycated haemoglobin was $13 \cdot 7 \%(3 \cdot 4 \%)$ and fructosamine concentration was $367(84) \mu \mathrm{mol} / \mathrm{l}$.

Table II shows the doses of glibenclamide taken by the patients at each of the visits. Nearly all the patients made their visits in the defined time windows.

Table III shows the characteristics of the three groups at the start and end of Ramadan, and table IV shows the analysis of covariance for the main results. There was no significant group effect, but there was a significant centre effect, indicating that patient's level of diabetic control varied with the centre that they were attending. The analysis also showed a groups $\times$ centres interaction for glycated haemoglobin caused mainly by one study centre: at centre 3 glycated haemoglobin increased during Ramadan in the control group (mean increase $0.9 \%$ ) and in the fasting group with a full dose of glibenclamide $(1.3 \%)$ but increased only slightly in the third group $(0.5 \%)$. The patients attending centre 3 were the youngest in the study with the shortest duration of diabetes, the lowest doses of glibenclamide, the lowest blood pressure, and the fewest concomitant 
TABLE IV-Analysis of covariance of percentage glycated haemoglobin and fructosamine concentration at end of Ramadan. Results from 542 patients

\begin{tabular}{|c|c|c|c|c|c|c|c|c|}
\hline \multirow[b]{2}{*}{ Source } & \multicolumn{4}{|c|}{ Percentage glycated haemoglobin } & \multicolumn{4}{|c|}{ Fructosamine concentration } \\
\hline & $\begin{array}{l}\text { Sum of } \\
\text { squares }\end{array}$ & df & F Value & $\begin{array}{c}\text { Probability } \\
(p(>F))\end{array}$ & $\begin{array}{l}\text { Sum of } \\
\text { squares }\end{array}$ & df & F Value & $\begin{array}{c}\text { Probability } \\
(p(>F))\end{array}$ \\
\hline $\begin{array}{l}\text { Covariate* } \\
\text { Groups } \\
\text { Centres } \\
\text { Groups } \times \text { centres } \\
\text { Error }\end{array}$ & $\begin{array}{r}2151 \cdot 58 \\
6 \cdot 22 \\
156 \cdot 68 \\
63 \cdot 80 \\
2388 \cdot 26\end{array}$ & $\begin{array}{r}1 \\
2 \\
4 \\
8 \\
526\end{array}$ & $\begin{array}{r}473.87 \\
0.69 \\
8.63 \\
1.76\end{array}$ & $\begin{array}{l}0.0001 \\
0.5045 \\
0.0001 \\
0.0832\end{array}$ & $\begin{array}{r}815328 \\
2491 \\
277610 \\
74957 \\
3876908\end{array}$ & $\begin{array}{r}1 \\
2 \\
4 \\
8 \\
526\end{array}$ & $\begin{array}{r}110 \cdot 62 \\
0 \cdot 17 \\
9 \cdot 42 \\
1 \cdot 27\end{array}$ & $\begin{array}{l}0.0001 \\
0.8446 \\
0.0001 \\
0.2560\end{array}$ \\
\hline
\end{tabular}

*Covariate is percentage glycated haemoglobin or fructosamine concentration at the start of Ramadan

TABLE V-Characteristics of patients at the start and end of Ramadan according to the study centre they attended. Figures are means (standard deviations)

\begin{tabular}{|c|c|c|c|c|c|}
\hline & \multicolumn{5}{|c|}{ Study centre No } \\
\hline & $\begin{array}{c}1 \\
(n=78)\end{array}$ & $\begin{array}{c}2 \\
(n=173)\end{array}$ & $\begin{array}{c}3 \\
(n=95)\end{array}$ & $\begin{array}{c}4 \\
(n=87)\end{array}$ & $\begin{array}{c}5 \\
(n=101)\end{array}$ \\
\hline \multicolumn{6}{|c|}{ Fructosamine concentration $(\mu \mathrm{mo} / \mathrm{h})$ : } \\
\hline At start of Ramadan & $336(78)$ & $381(98)$ & $358(78)$ & $365(75)$ & $410(67)$ \\
\hline At end of Ramadan & $324(80)$ & $380(97)$ & $396(99)$ & $403(104)$ & $419(91)$ \\
\hline \multicolumn{6}{|c|}{ Glycated haemoglobin (\%): } \\
\hline At start of Ramadan & $11.7(3.7)$ & $14 \cdot 0(3 \cdot 8)$ & $13.0(3.0)$ & $14 \cdot 1(3 \cdot 7)$ & $15 \cdot 0(2 \cdot 8)$ \\
\hline At end of Ramadan & $11 \cdot 8(3 \cdot 1)$ & $14 \cdot 2(3 \cdot 1)$ & $13.9(2 \cdot 8)$ & $14 \cdot 6(3 \cdot 1)$ & $15 \cdot 4(2 \cdot 5)$ \\
\hline
\end{tabular}

TABLE VI-Number of hypoglycaemic events (number of affected patients) reported by patients during study

\begin{tabular}{|c|c|c|c|c|}
\hline Groups of patients ${ }^{\star}$ & $\begin{array}{l}\text { During } \\
\text { run in }\end{array}$ & $\begin{array}{c}\text { During } \\
\text { Ramadan }\end{array}$ & $\begin{array}{l}\text { During } \\
\text { follow up }\end{array}$ & Total \\
\hline Control & $16(15)$ & $11(9)$ & $8(6)$ & $35(30)$ \\
\hline Full dose of glibenclamide & $19(13)$ & $14(10)$ & $16(12)$ & $49(35)$ \\
\hline Reduced dose of glibenclamide & $18(15)$ & $10(9)$ & $8(6)$ & $36(30)$ \\
\hline Total & $53(43)$ & $35(28)$ & $32(24)$ & $120(95)$ \\
\hline
\end{tabular}

«See text for details of groups.

diseases. Table V shows patients' characteristics according to the study centre that they attended. The patients at centre 3 showed an increase in fructosamine concentration and percentage of glycated haemoglobin during Ramadan, and the patients at centre 4 showed an increase in fructosamine concentration alone.

Table VI shows that the incidence of hypoglycaemia did not differ among the three groups and that the events occurred evenly throughout the study. Laboratory values of all features studied did not differ among the three groups, but in the two fasting groups the mean serum creatinine concentrations rose during Ramadan from $9 \cdot 71$ to $11.22 \mu \mathrm{mol} / 1$ for those taking full doses of glibenclamide and from 9.58 to 10.99 $\mu \mathrm{mol} / 1$ for those taking reduced doses though they were not outside the normal range (upper limit of 14 $\mu \mathrm{mol} / \mathrm{l})$.

Subgroup analyses for glycated haemoglobin and fructosamine were performed to see whether the 85 patients with well controlled diabetes (fructosamine concentration $<285 \mu \mathrm{mol} / \mathrm{l}$ ) reacted differently from the 457 patients with generally poorly controlled diabetes; whether loss or gain of $>2 \mathrm{~kg}$ of body weight had an influence (weight increased in 115 patients, decreased in 68 , and did not change in 353); or whether high or low plasma creatinine concentrations $(>10.8 \mu \mathrm{mol} / \mathrm{l}$ and $<8.7 \mu \mathrm{mol} / \mathrm{l}$ ) at entry to the study were important (at the start of Ramadan concentrations were low in 152 patients, medium in 254, and high in 136). All these subgroup analyses showed that all study groups behaved comparably, there were no significant interactions between the groups and the ex post subgroups in covariance analysis.

\section{Discussion}

We found that glibenclamide treatment was effective and safe for patients with non-insulin dependent diabetes who fasted during Ramadan compared with non-fasting patients in the same environment. In particular, no excess of hypoglycaemic events were reported during fasting compared with before and after Ramadan. As we had expected, patients attending different study centres showed different levels of diabetic control. This could have been due to the different eating habits of different social classes. The equal distribution of hypoglycaemic events (of which only four were considered serious and which were usually signalled by hunger and dizziness) between the three groups and during the study is, we believe, a good indication that the change of lifestyle had no effect on circadian rhythms.

The increases in creatinine concentrations although still within normal limits, suggest that doctors should advise their fasting patients to drink more fluid during Ramadan. These findings are supported by studies of healthy subjects, which found significant increases in creatinine concentrations during Ramadan. ${ }^{1015}$

Our study was unique in its large scale, use of one drug, and reflection of real drug treatments in an Islamic country. In contrast to other studies our study was designed to demonstrate external validity, and women outnumbered men by two to one-a ratio similar to that found in the community. ${ }^{16}$ The methods we used for monitoring glycaemic control were highly sensitive and we used a single laboratory. Our results cast doubt on those produced in the largest study published so far (51 subjects), in which significant changes in fructosamine and glycated haemoglobin $\left(\mathrm{HbA}_{1 \mathrm{lc}}\right)$ during Ramadan were reported. 6 Our conclusion is supported by the results of Suliman et al, who found that fasting had no measurable impact on glycaemic control. ${ }^{5}$

In conclusion, our findings support what many doctors have practised empirically for some years- to switch the morning dose (together with any midday dose) of glibenclamicie with that taken at sunset. ${ }^{17}$ Although the question of the management of patients on a single dose was not addressed by this study, we believe that our findings support the recommendation to take that dose unchanged with the first meal after sunset.

\section{Public health implications}

- A basic principle of Islam is fasting from sunrise to sunset during the month of Ramadan

- This poses obvious problems for diabetic patients

- Patients with non-insulin dependent diabetes who were fasting reversed their normal morning and evening doses of glibenclamide and added any midday dose to that taken in the evening

- The patients' diabetes remained as well controlled as that of patients who did not fast

- Reversal of normal morning and evening treatments is effective for patients with noninsulin dependent diabetes who are fasting 
This study was sponsored by Hoechst AG. We thank A Roudani, Laboratoires CIRAB, Casabalanca, for the laboratory measurements; $P$ Herrmann and coworkers, Laboratoires Polymedic, Casablanca, for logistical support; G Gammel, Central Nervous Drug Research, Bensheim, Germany, for the statistical evaluation; $H$ Noack, Hoechst AG, for statistical appraisal; $M$ Uhl, Hoechst AG, for monitoring; and, especially, all the nursing staff for their dedication.

1 Rashed AH. The fast of Ramadan. No problems for the well: the sick should avoid fasting. BMF 1992;302:521-2.

2 Rashed AH. Clinical problems during fast of Ramadan. Lancet 1989;i:1396.

3 Sulimani RA, Famuyiwa FO, Laajam MA. Diabetes mellitus and fasting: the need for a critical appraisal. Diabetic Med 1988;5:589-91.

4 International Diabetes Federation. IDF Directory 1991. Brussels: IDF, 1991

5 Sulimani RA, Laajam M, Al-Attas O, Famuyiwa FO, Bashi S, Mekki MO et al. The effect of Ramadan fasting on diabetes control in type II diabetic patients. Nutrition Research 1991;11:261-4.

6 Chamakhi S, Ftouhi B, Ben Rhomdhane N, Ghorbal S, Ben Khalifa F. Influence du jeune de Ramadan sur l'equilibre glycemique chez les diabetiques. Proceedings of the 3rd meeting of the Mediterranean group for the study of diabetes, Nice, France, November 29-December 2, 1990. Medicographia 1991;13 (suppl 1):27-9.

7 Abu Jayyab A, Al-Nakhi A, Richens ER, Siboo R, Ai-Khafaii M, Behbehan
$K$. The effect of fasting on the metabolic control of non-insulin dependent diabetes. Medical Principles and Practice 1989:1:214-20.

8 Chandalia HB, Bhargaav A, Kataria V. Dietary pattern during Ramadan fasting and its effect on the metabolic control of diabetes. Practical Diabetes $1987 ; 4: 287-90$

9 Chea SH, Ch'Ng SL, Husain R, Duncan MT. Effects of fasting during Ramadan on urinary excretion in Malaysian Muslims. $\mathrm{Br}$ f Nutr 1990;63: 329-37.

10 El-Hazmi MAF, Al-Faleh FZ, Al-Mofleh IA. Effect of Ramadan fasting on the values of haematological and biochemical parameters. Saudi Medical foumal 1987;8:171-6.

11 Kruse-Jarres JD, Jarausch J, Lehmann P, Vogt BW, Rietz P. A new colorimetric method for the determination of fructosamine. Laboratoriums Medizin 1989;13:245.

12 Teupe B. Quantitative determination of glycated hemoglobin using affinity chromatography. Ohio: ISOLAB, 1987.

13 Armitage $P$, Berry G. Statistical methods in medical research. Oxford: Blackwell, 1987.

14 Hochberg Y, Tamhane AC. Multiple comparison procedures. New York: Wiley,

15 Schmahl FW, Metzler B. The health risks of occupational stress in Islamic industrial workers during the Ramadan fasting period. Pol $f$ Occup Med 1991;4:219-28.

16 Simmons D, Williams DRR, Powell MJ. The Coventry Diabetes Study: prevalence of diabetes and impaired glucose tolerance in Europeans and Asians. Qf Med 1991;81:1021-30.

17 Elhamy $R$, Yacout $T$, Ishak $K$. Guidelines to the fasting diabetic patient during Ramadan. Frankfurt: Hoechst AG, 1993.

(Accepted 29 April 1993)
Institut National de la Santé et de la Recherche Médicale, Unit 21, Hôpital Paul Brousse, 94807 Villejuif, France

B Balkau, research scientist

E Eschwège, director of

research

L Papoz, director of research

Institut National de la Santé et de la Recherche Médicale, Unit 258,

Hôpital Broussais, 75674

Paris, France

J-L Richard, director of

research

$P$ Ducimetière, director of research

Laboratoire de la Direction de l'Action Sociale, de

l'Enfance et de la Santé, Centre Médico-Social, 75013 Paris, France

J-R Claude, professor

J-M Warnet, professor

Correspondence to: Dr Balkau.

BMF 1993;307:295-9

\section{5}

Risk factors for early death in non-insulin dependent diabetes and men with known glucose tolerance status

B Balkau, E Eschwège, L Papoz, J-L Richard, J-R Claude, J-M Warnet, P Ducimetière

\section{Abstract}

Objective-To identify risk factors for all cause mortality according to glucose tolerance status.

Design-Cohort study with an average 15.6 years' follow up.

Setting-Paris, France.

Subjects-7166 working men aged 44-55 in 1968-72 in the Paris prospective study cohort, with noninsulin dependent diabetes or known result of two hour $75 \mathrm{~g}$ oral glucose tolerance test.

Main outcome measures-Risk factors for death from all causes.

Results-128 men were known to be diabetic, 180 had diabetes diagnosed, and 697 had impaired glucose tolerance diagnosed. Compared with normoglycaemic men the relative risks of death in these groups were 2.0 (95\% confidence interval 1.4 to 3.0$)$, $2.7(2.0$ to 3.6$)$, and $1.6(1.3$ to 2.0$)$ respectively. Obesity, smoking, high blood pressure, and high non-esterified fatty acid concentration were risk factors for death in all subjects and were unaffected by glucose tolerance. The risks for fasting and two hour insulin concentrations and mean corpuscular volume were two times higher in known diabetic men than in men not known to be diabetic. Central obesity was significant only in men not known to be diabetic (1.6 (1.4 to 1.9$))$. In known diabetic men a two hour glucose concentration higher than $11 \cdot 1$ $\mathrm{mmol} / \mathrm{l}$ carried a relative risk of death of $3.8(1.4$ to 9.4).

Conclusions-Diabetic men have similar risk factors for early mortality to other men but are at higher risk from hyperinsulinaemia, hyperglycaemia, and high mean corpuscular volume.

\section{Introduction}

Subjects with non-insulin dependent diabetes have a reduced life span, with an age specific mortality about twice that of the general population. ${ }^{1}$ This excess mortality has been attributed principally to ischaemic heart disease. ${ }^{1}$ Our analysis of the 44-55 year old men in the Paris prospective study cohort showed that diabetic subjects (known and newly diagnosed) had an increased risk of death from other causes as well. Compared with subjects who were normoglycaemic, the diabetic subjects had a relative risk of death from all causes of $2.31(95 \%$ confidence interval 1.81 to 2.93$)$ after 15 years of follow up, similar to that for coronary heart disease $2 \cdot 26(1 \cdot 25$ to $3 \cdot 79){ }^{2}$ These results parallel those from the Gothenburg study of middle aged men, which reported odds ratios of $3.5(2.5$ to 6.9$)$ for death and 4.1 $(2.5$ to 6.6$)$ for death from coronary heart disease in known diabetic subjects after seven years of follow up. ${ }^{3}$ We analysed risk factors associated with death in diabetic men.

\section{Subjects and methods}

At the beginning of 1967, 8297 male civil servants born between 1917 and 1928 were eligible to participate in the Paris prospective study of cardiovascular risk factors. The general aims and detailed methods of this study, as well as the characteristics of this population, have been described. ${ }^{45}$ Of the 8297 subjects, $96 \%$ were examined initially, and a further $3 \%$ were excluded from analysis because they were born outside France. At the first annual follow up examination 7038 of the men (aged 44-55 years) completed a two hour $75 \mathrm{~g}$ oral glucose tolerance test. A further 128 subjects were known to have diabetes and had been or were being treated with hypoglycaemic drugs; the ten men receiving insulin were not included. All subjects who were not known to be diabetic were classified, on the basis of their fasting and two hour glucose concentrations and the World Health Organisation 1985 criteria. ${ }^{6}$ Newly diagnosed diabetes was defined as fasting glucose $\geqslant 7.8 \mathrm{mmol} / 1$ or two hour glucose $\geqslant 11.1$ $\mathrm{mmol} / \mathrm{l}$, or both; impaired glucose tolerance as fasting glucose $<7.8 \mathrm{mmol} / \mathrm{l}$ and two hour glucose $7 \cdot 8-11 \cdot 1$ $\mathrm{mmol} / \mathrm{l}$; and normoglycaemia as fasting glucose $<7 \cdot 8$ $\mathrm{mmol} / \mathrm{l}$ and two hour glucose $<7.8 \mathrm{mmol} / \mathrm{l}$.

The men were asked about their smoking habits. Body mass index (weight/(height) $)^{2}\left(\mathrm{~kg} / \mathrm{m}^{2}\right)$ ), central obesity (ratio of iliac and thigh circumferences), ${ }^{7}$ and blood pressure (measured with the subject in a 